\title{
Effective particle dispersion via high-shear mixing of the electrolyte for electroplating a nickel-molybdenum disulphide composite
}

\author{
Nan Zhou*, Shuncai Wang, Frank C. Walsh \\ national Centre for Advanced Tribology at Southampton (nCATS) and Materials Engineering \\ Research Group, Department of Mechanical Engineering, University of Southampton, \\ Southampton SO17 1BJ, UK. \\ * Author for correspondence; Email: Nan.Zhou@ soton.ac.uk
}

\begin{abstract}
The hydrophobic nature of molybdenum disulphide $\left(\mathrm{MoS}_{2}\right)$ particles is a major challenge for electrodepositing uniform $\mathrm{Ni}-\mathrm{MoS}_{2}$ composite coatings due to particle agglomerates present in the aqueous nickel plating bath. In this study, high-shear mixing was shown for the first time as a facile and effective way to achieve a narrow particle-size distribution and stable particle dispersions in the electrolyte, which were characterised by measuring particle-size distributions via dynamic light scattering. The influence of shear mixing duration and speed on particle dispersion in the electrolyte was investigated. The resulting Ni-MoS 2 composite coating had a compact structure, showing a lower coefficient of friction and enhanced wear resistance in unlubricated wear tests. In comparison, magnetic stirring was less effective in breaking down particle agglomerates in the bath, which led to a porous and fragile deposit with poor tribological properties.
\end{abstract}

Keywords: composite coating, molybdenum disulphide, nickel electrodeposition, high-shear mixing, tribology. 


\section{Introduction}

The electrodeposition of nickel-based composite coatings via inert particles suspended in the plating bath results in high performance coatings for tribological engineering applications [1]. Selflubricating composite coatings in particular received wide interests for their low friction properties that could reduce energy consumption and wear in mechanical systems, with various incorporated solid lubricant particles such as polytetrafluoroethylene (PTFE), graphite, molybdenum disulphide $\left(\mathrm{MoS}_{2}\right)$ and tungsten disulphide $\left(\mathrm{WS}_{2}\right)$ [2]. Molybdenum disulphide $\left(\mathrm{MoS}_{2}\right)$ is an excellent solid lubricant when applied directly in vacuum, added into lubricant oils or dispersed in composite materials, with its lubricity arising from a layered molecular structure and weak inter-molecular bonding forces between the sulphur atoms [3].

Nickel-based composite coatings with embedded $\mathrm{MoS}_{2}$ particles have been developed to reduce friction and wear for critical mechanical components in advanced automobile and aerospace applications [4-9]. The addition of $\mathrm{MoS}_{2}$ particles can modify the microstructure, internal stress, composition and wear behaviour of the coatings, many of them showing lower friction against steel and improved wear resistance compared to coatings without particles. Operational parameters may affect the composition and tribological performance of the deposits. Particle concentration and degree of dispersion in the electrolyte are major factors. A wide range of particle concentrations in the bath has been reported, as shown in Table 1, some using lower concentrations of $1-2 \mathrm{~g} \mathrm{dm}^{-3}[5$, 7, 9] and others higher concentrations of up to $30 \mathrm{~g} \mathrm{dm}^{-3}[4,6,8]$. The optimum particle concentration in the bath may vary depending on the deposition conditions but it should be kept as low as possible in order to control the running and bath inventory costs.

A major challenge for electrodeposited $\mathrm{Ni}-\mathrm{MoS}_{2}$ composite coatings is that $\mathrm{MoS}_{2}$ particles are hydrophobic and tend to form large agglomerates in the aqueous nickel plating bath. This prevents 
a uniform particle suspension being achieved and may negatively affect particle incorporation into the nickel matrix, resulting in an increased particle concentration being required. Unstable particle dispersion can also result in fragile and porous deposits $[8,10]$, which are prone to suffer from abrasive wear and corrosion. Studies for composite electrodeposition have often used magnetic stirring with surfactants for particle dispersion due to the convenience of the technique for an easy set-up. However, magnetic stirring can be time-consuming with reports quoting a stirring time for $\mathrm{MoS}_{2}$ particle dispersion of up to $12 \mathrm{~h}$ [11], which is impractical for industrial application. Furthermore, its effectiveness in particle dispersion remains unclear. From the literature survey summarised in Table 1, some of the composite coatings showing the lowest coefficient of friction reported were produced from particle dispersions via less conventional methods, such as ultrasonication of the electrolyte [6] or high-energy reaction ball milling of particulates before suspension in the bath [8]. Studies on different composite coatings have pointed out that magnetic stirring may not disperse other types of particles $\left(\mathrm{TiO}_{2}, \mathrm{SiC}, \mathrm{WS}_{2}, \mathrm{BN}\right)$ effectively [12 - 14]. Defects such as non-uniform particle distribution and porous coating structures as a result of particle agglomeration can significantly lower the tribological performance of the composite coatings. Therefore, it is very important to identify facile and effective particle dispersion methods other than magnetic stirring for successful electrodeposition of composite coatings.

Ultrasonication has been frequently reported as a means for particle dispersion both before and during composite electrodeposition, which is summarised in a review [15]. The ultrasonic source may be a custom-made transducer for industrial trials, and an ultrasonic bath or probe for small bench operations. The outcome of ultrasonication may be influenced by ultrasonic bath/probe setup, sample position, ultrasound frequency and power density at the sample surface, etc. Under suitable conditions, ultrasonication may provide a more effective particle dispersion than magnetic stirring, enabling more uniform composite coatings to be achieved. The drawbacks of ultrasonication may include noise pollution and heating of the bath. Adequate ear protection must 
be provided when working in the presence of strong ultrasonic sources and an additional cooling system for heat management may add to the cost of the operation.

An alternative mechanical agitation method to aid particle dispersion during bath preparation is high-shear mixing. High-shear mixing is often used to produce bulk mixtures of normally immiscible components, such as pigments in paint coatings. Such mixing has shown the ability to achieve very stable dispersions that would otherwise be difficult by commonly used stirring procedures [16]. A high-shear mixer generates large fluid velocity differences, hence shear, around a high-speed rotor blade. The mixing head also contains a stator with a close-clearance gap from the rotor, forming an extremely high-shear zone for materials exiting the rotor. Important parameters for high-shear mixing operations are mixing speed and time. A study on the effect of high-shear mixing speed and time on GNP/epoxy composites [17] found that a high mixing speed $\left(9000 \mathrm{rev} \mathrm{min}^{-1}\right)$ and a long shear-mixing time $(2 \mathrm{~h})$ could reduce the size of particle agglomerates by almost $70 \%$ compared to mixing at lower speeds $\left(1000-7000 \mathrm{rev} \mathrm{min}^{-1}\right)$. The potential for applying high-shear mixing to particle dispersion in composite electrodeposition is promising but has never been systematically studied.

This study pioneers in using high-shear mixing as an alternative agitation method for particle dispersion in electrodeposition of robust and self-lubricating Ni-MoS ${ }_{2}$ composite coatings. The high-shear mixer in this study was designed for a multiple pass of materials through the rotor-stator array during turbulent mixing, creating a higher number of shear events that may result in a very narrow particle-size distribution. The resulting coating also showed one of the lowest coefficients of dry friction reported for electrodeposited $\mathrm{Ni}-\mathrm{MoS}_{2}$ composite coatings. The aim of this work is to study the effectiveness of high-shear mixing for $\mathrm{MoS}_{2}$ particle dispersion prior to composite electrodeposition when compared to magnetic stirring. A modified Watts nickel bath containing wetting and levelling additives was used. Surface microstructures and cross-sectional analysis of 
the composite coatings are presented. Tribological properties of the composite coatings in terms of friction and wear are also investigated.

\section{Experimental details}

This study employs a Watts nickel bath for the electrodeposition of Ni-MoS 2 composite coatings. The Watts bath is widely used in industry for depositing nickel coatings [18] due to its high current efficiency and low cost. The $\mathrm{MoS}_{2}$ particles were supplied by Shanghai ST-Nano Science \& Technology Co. Ltd $(99.9 \%, 1-2 \mu \mathrm{m}$, Figure 1 a). The composition of the bath is summarised in Table 2 and 3.

Prior to composite electrodeposition, $\mathrm{MoS}_{2}$ particles and surfactants were carefully weighed added into a glass vial $(20 \mathrm{~mL})$ with a Watts nickel bath $(10 \mathrm{~mL})$.The contents in the glass vial were subjected to magnetic stirring (PTFE-coated cylindrical stirring bar, diam. $3 \mathrm{~mm}, \mathrm{~L} 8 \mathrm{~mm}, 2000 \mathrm{rev}$ $\min ^{-1}$ ) or high-shear mixing (Silverson ${ }^{\circledR}$ L4RT high-shear mixer with a $1 \mathrm{~cm}$ 'Mini-Micro' stainless steel workhead rotating at 8000 rev min $^{-1}$ inside a stator, as shown in Figure 1 (b) and (c).

Particle dispersions prepared by high-shear mixing and magnetic stirring were analysed by dynamic light scattering and laser doppler micro-electrophoresis for particle size distribution and zeta potential respectively in a Zetasizer Nano ZS system (Malvern Instruments Ltd.) [19]. A mixture of $\mathrm{MoS}_{2}$ particles $\left(2 \mathrm{~g} \mathrm{dm}^{-3}\right)$ in the Watts bath $(10 \mathrm{~mL})$ together with appropriate additives was subjected to a controlled mechanical agitation for a set time. After mixing, the dispersion was immediately transferred into a cuvette for particle-size distribution measurement. 
Electrodeposition was carried out using a mild steel plate cathode (AISI 1020, $80 \mathrm{~mm} \times 20 \mathrm{~mm} \times 3$ $\mathrm{mm})$ and a nickel plate anode $(80 \mathrm{~mm} \times 20 \mathrm{~mm} \times 1 \mathrm{~mm})$. The electrodes were sealed with waterproof tape, leaving an exposed surface area of $30 \mathrm{~mm} \times 20 \mathrm{~mm}$ each for plating in a parallelplate cell configuration as shown in Figure 1 (d) and (e). The substrate was degreased in acetone, polished with Silicon Carbide ( $\mathrm{SiC}$ ) paper in the order of 120, 800 and 1200 grit grade, activated in $1 \mathrm{~mol} \mathrm{dm}^{-3} \mathrm{HCl}$ for $60 \mathrm{~s}$ and rinsed with deionised water prior to electrodeposition. Particle dispersions were diluted to $80 \mathrm{~mL}$ with Watts nickel electrolyte in a $100 \mathrm{~mL}$ cylindrical beaker. The bath composition and plating conditions are summarised in Table 2 and Table 3.

Microscopic analysis of Ni-MoS 2 composite coating surfaces was carried out using optical microscopy (Alicona), and scanning electron microscopy (SEM, JSM 6500) coupled with backscattered electron imaging (BEI) and energy-dispersive X-ray spectroscopy (EDX).

The tribological tests were conducted on a TE-77 reciprocating tribometer. An AISI-52100 bearing steel cylinder roller counterpart was used with a hardness of $c a$. $900 \mathrm{Hv}$, a diameter of $6 \mathrm{~mm}$, and a length of $10 \mathrm{~mm}$. The load applied was $20 \mathrm{~N}$, giving a Hertzian line contact pressure of $c a \cdot 0.12$ GPa with a sliding frequency of $1 \mathrm{~Hz}$, and a stroke length of $10 \mathrm{~mm}$ at $22{ }^{\circ} \mathrm{C}$ at a relative humidity of $50 \%$.

\section{Results and discussions}

\subsection{Visual appearance of particle dispersions}

Particle dispersions in deionised water $\left(\mathrm{MoS}_{2} 2 \mathrm{~g} \mathrm{dm}^{-3}\right.$, CTAB $0.1 \mathrm{~g} \mathrm{dm}^{-3}$, vol. $\left.10 \mathrm{~mL}\right)$ were prepared via magnetic stirring (2000 rev $\mathrm{min}^{-1}, 30 \mathrm{~min}$ ) and high-shear mixing (8000 rev $\mathrm{min}^{-1}, 30$ min) in $20 \mathrm{~mL}$ cylindrical glass vials. The choice of water as the dispersant was due to the dark 
green colour of Watts nickel bath interfering with visual inspection. The mixtures were transferred into $10 \mathrm{~mL}$ measuring cylinders after mixing and were allowed to settle undisturbed for visual inspection of particle dispersion stability. Shortly after dispersing, the mixtures were dense and dark with no difference in visual appearance (Figure 2 a). After standing still for overnight (c.a.8 h), both mixtures became clearer indicating a progressive particle precipitation as shown in Figure 2 (b). A much clearer mixture with thick particle sediments was found for the dispersion using magnetic stirring, indicating a higher particle precipitation rate. The dispersion via high-shear mixing was more uniform and stable, showing a darker colour and only a slight extent of particle precipitation.

\subsection{Particle size distribution and zeta potential in dispersions}

Particle dispersions in a Watts nickel bath were analysed by a Zetasizer Nano ZS (Malvern Instruments). The refractive index for $\mathrm{MoS}_{2}$ particles and a Watts nickel bath were chosen from existing data in the software. In the case of the Watts nickel bath, the effect of individual components at the given concentrations were added separately to the profile refractive index of water to make up the complex refractive index of the bath.

Figure 3 (a) shows the relationship between particle Z-average size and high-shear mixing speed each with a mixing time for $1 \mathrm{~h}$. A particle Z-average size of $1715 \mathrm{~nm}$ was found at a high-shear mixing speed of $3000 \mathrm{rev} \mathrm{min}^{-1}$, indicating the presence of large particle agglomerates. The particle Z-average size decreased by almost 33\% (from $1715 \mathrm{~nm}$ to $1150 \mathrm{~nm}$, Figure $3 \mathrm{a}$ ) as the high-shear mixing speed increased from $3000 \mathrm{rev} \mathrm{min}^{-1}$ to $7000 \mathrm{rev} \mathrm{min}^{-1}$. Compared to the particle size (c.a. $2000 \mathrm{~nm}$ ) after an initial pre-mixing via mechanical stirring at $2000 \mathrm{rev} \min ^{-1}$, the decrease was almost $43 \%$. There was a small trend of further decrease of particle Z-average size for mixing speeds higher than 7000 rev $\min ^{-1}$, but the changes were relatively small compared to those at 
lower mixing speeds. For magnetic stirring, the maximum stirring speed available from the stirring plate (2000 rev $\mathrm{min}^{-1}$ ) was applied to achieve a satisfactory particle dispersion. The Zetasizer only measures particle agglomerate sizes less than $10 \mu \mathrm{m}$ in diameter and magnetic stirring at lower stirring speeds would simply not produce a uniform solid-liquid mixture or result in large agglomerates outside the measuring range of the available instrument.

Figure 3 (b) shows the relationship between particle Z-average size and duration of agitation via magnetic stirring at $2000 \mathrm{rev} \mathrm{min}^{-1}$ and high-shear mixing at $8000 \mathrm{rev} \mathrm{min}{ }^{-1}$. During the first $25 \mathrm{~min}$ into mixing, particle Z-average size in the dispersion via high-shear mixing saw a steep decline from $1900 \mathrm{~nm}$ to $1332 \mathrm{~nm}$, and reached a stabilised value around $1180 \mathrm{~nm}$ after $100 \mathrm{~min}$. In the dispersion via magnetic stirring, the particle Z-average size was eventually reduced from $1996 \mathrm{~nm}$ to only $1518 \mathrm{~nm}$, which took a longer period of about $100 \mathrm{~min}$. This indicates that high-shear mixing is more effective in breaking down particle agglomerations to smaller sizes over a much shorter period than magnetic stirring.

Figure 3 (c) shows the particle zeta potential measurement of particle dispersions during mixing. Particle dispersion via high-shear mixing showed a positive zeta potential of around $31-32 \mathrm{mV}$, which is slightly higher than $30.5-31.5 \mathrm{mV}$ for particle dispersion produced via magnetic stirring. There was more fluctuation at the beginning of mixing, but further mixing seemed to have little influence on particle zeta potential. The positive zeta potential indicated that $\mathrm{MoS}_{2}$ particle dispersions are moderately stable in the Watts nickel bath. During electrodeposition, continuous agitation is essential to maintain the stability of particle dispersion. 
Figure 4 shows the optimum particle-size distribution measurement of $\mathrm{MoS}_{2}$ particle dispersions under the two different methods studied: magnetic stirring (2000 rev $\min ^{-1}, 3 \mathrm{~h}$ ) and high-shear mixing (8000 rev $\min ^{-1}, 3 \mathrm{~h}$ ). Particle-size distribution in the dispersion via magnetic stirring showed large particle agglomerates of up to $7 \mu \mathrm{m}$ in diameter in Figure 4 (a). High-shear mixing produced a narrow particle-size distribution with a Gaussian-alike curve ranging from $0.2 \mu \mathrm{m}$ to $1.9 \mu \mathrm{m}$. The middle particle size of the distribution was around $0.9 \mu \mathrm{m}$ in Figure 4 (b), which is very close to the particle size given by the manufacturer $(1-2 \mu \mathrm{m})$. The notable improvement of particle dispersion by reducing agglomerate sizes has also been reported in literature $[17,20]$ for the high-shear mixing method.

\subsection{Structure and surface morphology of Ni-MoS 2 composite coatings}

Figure 5 shows the optical camera photos of pure nickel and $\mathrm{Ni}-\mathrm{MoS}_{2}$ composite coatings deposited on mild steel substrates with particle dispersions via high-shear mixing $\left(8000 \mathrm{rev} \mathrm{min}^{-1}, 3\right.$ h) and magnetic stirring (2000 rev $\min ^{-1}, 3 \mathrm{~h}$ ). The photos reflect the appearance of the coatings as perceived by a visual inspection. The reference nickel deposit (Figure 5 a) was bright and smooth, showing a metallic gloss under room light. Ni-MoS 2 composite coating using particle dispersion via high-shear mixing was dull and light grey (Figure $5 \mathrm{~b}$ ). A darker deposit was produced using particle dispersion via magnetic stirring (Figure $5 \mathrm{c}$ ).

Figure 6 shows the XRD patterns of $\mathrm{MOS}_{2}$ powder (Figure 6 a) and nickel / composite coatings (Figure $6 \mathrm{~b}-\mathrm{d}$ ). The $\mathrm{MoS}_{2}$ peaks are present in both composite coatings but are more intense in $\mathrm{Ni}$ $\mathrm{MoS}_{2}$ composite coating with particle dispersion via magnetically stirring, indicating a higher $\mathrm{MoS}_{2}$ particle content. The crystallite size calculated according to Debye-Scherrer equation from the half peak widths of $\mathrm{Ni}(110)$, (200) and (220) peaks was $10 \mathrm{~nm}$ for pure Ni coating (Figure $6 \mathrm{~b}$ ), $20.8 \mathrm{~nm}$ for Ni-MoS 2 composite coating from a bath with particle dispersion via magnetically 
stirring (Figure $6 \mathrm{c}$ ) and $27.8 \mathrm{~nm}$ for $\mathrm{Ni}-\mathrm{MoS}_{2}$ composite coating from a bath with particle dispersion via high-shear mixing (Figure $6 \mathrm{~d}$ ).

Nanoindentation measurements on the coatings showed that microhardness of the coatings was 5.6 GPa for Ni coating, $4.92 \mathrm{GPa}$ for the Ni-MoS composite coating from a bath with particle dispersion via magnetically stirring and $4.62 \mathrm{GPa}$ for the Ni-MoS${ }_{2}$ composite coating from a bath with particle dispersion via high-shear mixing. The hardness value was consistent with XRD measurements and indicated that an increase in crystallite size reduced the microhardness of the coating.

SEM surveys revealed microscopic surface roughness features on $\mathrm{Ni}-\mathrm{MoS}_{2}$ composite coatings. Ni$\mathrm{MoS}_{2}$ composite coating using particle dispersion via high-shear mixing showed small and densely packed nodular structures in Figure 7 (a), with a $\mathrm{MoS}_{2}$ surface content of 8.7 wt.\% as reported by EDX analysis. Ni-MoS 2 composite coating using particle dispersion via magnetic stirring showed large, porous structures in Figure 7 (b) with a higher $\mathrm{MoS}_{2}$ content of 30 wt.\% by EDX.

Optical microscopic scans showed 3D surface structures of Ni-MoS 2 composite coatings in Figure 7. Surface roughness was measured by $S_{a}$ value (average height of selected area), with $S_{a}=18.48 \pm$ $2.58 \mu \mathrm{m}$ for $\mathrm{Ni}-\mathrm{MoS}_{2}$ composite coating using particle dispersion via high-shear mixing as shown in Figure 7 (c), and $S_{a}=49.80 \pm 3.23 \mu \mathrm{m}$ for Ni-MoS${ }_{2}$ composite coating using particle dispersion via magnetic stirring in Figure 7 (d). 
Elemental mapping by EDX showed uniform nickel distribution in composite coatings as shown in Figures 8 (c) and (d). The distribution of Mo contents (as an indicator of $\mathrm{MoS}_{2}$ presence) was more concentrated in surface protrusion structures as shown in Figure 8 (e) and (f).

The surface roughness measurement was a reflection of the porosity of the coating structure, which agreed with SEM observations and was further explained by cross-sectional BEI scans of the deposits in Figure 9. Under same electrodeposition conditions, pure nickel coating showed the highest level of compactness and smoothness, with a thickness of about $75 \mu \mathrm{m}$ in Figure 9 (a). A compact layer close to the mild steel substrate was found for $\mathrm{Ni}-\mathrm{MoS}_{2}$ composite coating using particle dispersion via high-shear mixing. The $\mathrm{MoS}_{2}$ content increased as the thickness of the coating increased, which was covered by a thin porous top layer of around $20 \mu \mathrm{m}$ as shown in Figure 9 (b). Ni-MoS 2 composite coating using particle dispersion via magnetic stirring revealed extensive porosities throughout the coating structure, with some cavities of over $50 \mu \mathrm{m}$, as shown in Figure 9 (c). The thickness of the porous layers were found to correlate well with surface roughness measurements by optical microscopy.

The presence of a porous layer in composite electrodeposition has also been observed where a conductive particle is involved $[5-14,21]$. Although surface roughness containing hierarchical structures may introduce enhanced catalytic and/or anti-wetting capabilities, the porous surface structures contained large amounts of defects, which would reduce the mechanical robustness of the deposit for potential tribological applications. It has been observed that metal deposition can occur on both incorporated conductive particles and the electrode surface. Under same deposition conditions, a more conductive particle could lead to a more porous composite coating structure [10,22]. Simulation work by Celis et al. [23] showed a higher current density distribution on the incorporated conductive particles on the surface of the cathode, leading to a localised acceleration of metal deposition that leads to dendritic or nodular structure growth. In Figure 9 (c) it could be 
clearly seen that the protruding structures resulted from the growth of nickel around incorporated $\mathrm{MoS}_{2}$ particles, forming protruding structures both small and large, which is a clear indication that $\mathrm{MoS}_{2}$ particles are conductive during electrodeposition. A non-uniform dispersion of conductive particles in bath could further increase the porosity of the coating, by introducing porosities from within large particle agglomerates as well as accelerating the growth of protrusions.

The above results showed the effect of particle dispersion stability on the composition and structure of the composite coatings. In order to achieve compact coating structures and uniform particle content distributions, stable particle dispersions are generally desired. Choosing vigorous mechanical agitations can avoid particle agglomerates in the bath that may otherwise lead to a porous and fragile composite coating.

\subsection{Non-lubricated wear tests of $\mathrm{Ni}-\mathrm{MoS}_{2}$ composite coatings}

Non-lubricated roller-on-plate tests were performed to evaluate the friction properties of the electrodeposited composite coatings. A TE-77 reciprocating tribometer was used. The coefficient of friction for Ni-MoS $\mathrm{M}_{2}$ composite coatings was presented as a function of test time in Figure 10. $\mathrm{Ni}-\mathrm{MoS}_{2}$ composite coating using particle dispersion via high-shear mixing showed over $50 \%$ reduction in running-in and steady-state coefficient of friction from those of $\mathrm{Ni}-\mathrm{MoS}_{2}$ composite coating using particle dispersion via magnetic stirring. The coefficient of friction for pure $\mathrm{Ni}$ coating was around 0.6 . It was evident that the presence of $\mathrm{MoS}_{2}$ particles significantly reduced dry sliding friction of the composite coating against the bearing steel counterpart. Wear track crosssectional depth profile showed a wear depth of $80 \mu \mathrm{m}$ for the Ni-MoS${ }_{2}$ composite coating using particle dispersion via magnetic stirring in Figure 11 (a), whereas a small wear depth of about 12 $\mu \mathrm{m}$ for the Ni-MoS${ }_{2}$ composite coating using particle dispersion via high-shear mixing was shown in Figure 11 (b). 
3D optical scans and SEM of the wear track surfaces showed that surface roughness features for $\mathrm{Ni}-\mathrm{MoS}_{2}$ composite coating using particle dispersion via high-shear mixing underwent polishing wear, with the top nodular structures being slightly flattened in Figure 12 (a) and (b). Surface roughness features for $\mathrm{Ni}-\mathrm{MoS}_{2}$ composite coating using particle dispersion via magnetic stirring were largely removed from the wear track, and a large amount of wear debris were found outside the wear track, showing extensive abrasive wear in Figure 12 (d) and (e).

EDX mapping showed a uniform distribution of Mo over both wear track surfaces compared to the coating surfaces before wear in Figure 12 (c) and (f). This is due to the $\mathrm{MoS}_{2}$ particles being sheared across the wear track, forming local tribofilms that contributed to the low friction in the wear test. Little wear was observed on the roller counterparts, however presence of $\mathrm{MoS}_{2}$ content over contact areas was found, indicating a transfer of tribofilm to the roller counterpart. Such effects have also been reported by He et al. [6].

In order to achieve maximum lubricity, $\mathrm{MoS}_{2}$ particles need to be sheared into tribo-films with the weakly bonded $\mathrm{MoS}_{2}$ intermolecular planes aligning parallel with the wear track [24,25]. The formation of the tribo-film separates the sliding surfaces, which not only provides a layer of easily sheared solid lubricant, but also reduces direct wear between the coating and bearing steel, hence the reduction in friction and wear. A compact and uniform coating provides a firm support for the $\mathrm{MoS}_{2}$ particles to allow an effective shear to take place, so that a low-friction tribo-film may readily develop. This can be seen in the tribological performances of $\mathrm{Ni}-\mathrm{MoS}_{2}$ composite coating using particle dispersion via high-shear mixing. The high coefficient of friction for $\mathrm{Ni}-\mathrm{MoS}_{2}$ composite coating from a bath involving particle dispersion via magnetic stirring can be attributed to the energy consumption in removals of the $\mathrm{MoS}_{2}$ rich but fragile surface roughness features under the load, which is shown from the deep wear and cracking on the wear track. The porosity of 
the composite coating makes a less effective pathway for $\mathrm{MoS}_{2}$ tribo-film formation in spite of a higher content of $\mathrm{MoS}_{2}$ in the coating.

For Ni-MoS 2 composite coatings, enhanced self-lubrication and wear resistance would tend to favour a compact coating structure with a uniform particle content distribution, which has been shown to result from a stable particle dispersion via effective means of mechanical agitation, such as high-shear mixing. Moreover, it has also been shown that particle content in the composite coating alone should not be regarded as the only criteria for assessing coating quality. In this study, a Ni-MoS 2 composite coating with a moderate but well-dispersed $\mathrm{MoS}_{2}$ particle content (8.7 wt.\%) showed better tribological performance than the one with a much higher but agglomerated $\mathrm{MoS}_{2}$ content (30 wt.\%). If the content of the solid lubricant particle is too low, it may sometimes lead to insufficient friction reduction. A much higher particle content, however, may result from large particle agglomerates in a porous and friable coating structure, resulting in excessive wear and increased friction for $\mathrm{Ni}-\mathrm{MoS}_{2}$ composite coatings. The particle distribution and content in a tribological coating must be carefully controlled to meet the demand of target functionality without compromising durability.

\section{Conclusions}

The effect of electrolyte agitation method on the stability of particle dispersions and the properties of resulting electrodeposited Ni-MoS 2 composite coatings has been studied.

High-shear mixing produced a particle dispersion with narrow particle-size distributions of 0.2 $-1.9 \mu \mathrm{m}$ compared to $2-7 \mu \mathrm{m}$ by magnetic stirring. It was shown to be a facile and effective way to achieve stable particle dispersions in the bath whereas magnetic stirring was much less effective 
in breaking down large particle agglomerates, leading to an unstable particle dispersion that quickly precipitates. The effective speed of high-shear mixing for particle dispersion should be higher than $7000 \mathrm{rev} \min ^{-1}$ for the type of blade head employed in this study, which reduced particle agglomerate sizes from $1700 \mathrm{~nm}$ to $1150 \mathrm{~nm}$ within $1 \mathrm{~h}$ at $8000 \mathrm{rev} \mathrm{min}^{-1}$.

Particle dispersion stability exhibited a significant influence on the structure and tribological performance of the resulting Ni-MoS 2 composite coatings. A uniform $\mathrm{MoS}_{2}$ particle dispersion in bath via high-shear mixing led to a compact Ni-MoS${ }_{2}$ coating, which showed a $\sim 50 \%$ reduction in coefficient of friction (from 1.6 to 0.08 ) and $~ 85 \%$ reduction of wear depth in unlubricated wear tests against bearing steel cylinder (from $80 \mu \mathrm{m}$ to $12 \mu \mathrm{m}$ after 900 seconds of reciprocating line contact) when compared with a porous $\mathrm{Ni}-\mathrm{MoS}_{2}$ coating from an unstable particle dispersion via magnetic stirring.

For future work, the effectiveness of high-shear mixing in dispersing other types of particles for composite electrodeposition could be studied. The stability of particle dispersions via various methods such as high-shear mixing and ultrasonication could also be compared, which would offer useful insight for improving the quality of electrodeposited composite coatings.

\section{Acknowledgements}

This work was supported by the Chinese Scholarship Council (CSC NO. 201608060099), the Faculty of Engineering and the Environment at University of Southampton (funding code F2XY5Y / 5104141107294) and the Royal Society International Exchanges Scheme (IE151191). 


\section{References}

[1] F.C. Walsh, C. P. de León, A review of the electrodeposition of metal matrix composite coatings by inclusion of particles in a metal layer: an established and diversifying technology, Transactions of the IMF 92 (2014) 83-98.

[2] K. Miyoshi, Solid lubricants and coatings for extreme environments: State-of-the-art survey, NASA Report (2007) 1-23.

[3] T. Gradt, T. Schneider, Tribological performance of $\mathrm{MoS}_{2}$ coatings in various environments, Lubricants 4 (2016) 32.

[4] Güler, E.S., Konca, E., Karakaya, I, Investigation of the tribological behaviour of electrocodeposited Ni-MoS2 composite coatings, International Journal of Surface Science and Engineering 11 (2017), pp. 418-432

[5] L. Shi, C. Sun, W. Liu, Electrodeposited nickel-cobalt composite coating containing $\mathrm{MoS}_{2}$, Applied Surface Science 254 (2008) 6880-6885.

[6] Y. He, S.C. Wang, F.C. Walsh, Y.L. Chiu, P.A.S. Reed, Self-lubricating Ni-P- $\mathrm{MoS}_{2}$ composite coatings, Surface and Coatings Technology 307 (2016) 926-934.

[7] M.F. Cardinal, P.A. Castro, J. Baxi, H. Liang, F.J. Williams, Characterization and frictional behavior of nanostructured $\mathrm{Ni}-\mathrm{W}-\mathrm{MoS}_{2}$ composite coatings, Surface and Coatings Technology 204 (2009) 85-90.

[8] G. Ma, B. Xu, H. Wang, X. Wang, G. Li, S. Zhang, Research on the microstructure and space tribology properties of electric-brush plated Ni/ $\mathrm{MoS}_{2}-\mathrm{C}$ composite coating, Surface and Coatings Technology 221 (2013) 142-149.

[9] Z. Li, J. Wang, J. Lu, J. Meng, Tribological characteristics of electroless Ni-P-MoS composite coatings at elevated temperatures, Applied Surface Science, 264 (2013) 516- 521.

[10] V.D. Stankovic, M. Gojo, Electrodeposited composite coatings of copper with inert, semiconductive and conductive particles, Surface and Coatings Technology 81 (1996) 225232.

[11] Z.J. Huang, D.S. Xiong, $\mathrm{MoS}_{2}$ coated with $\mathrm{Al}_{2} \mathrm{O}_{3}$ for $\mathrm{Ni}-\mathrm{MoS}_{2} / \mathrm{Al}_{2} \mathrm{O}_{3}$ composite coatings by pulse electrodeposition, Surface and Coatings Technology 202 (2008) 3208-3214. 
[12] T. Lampke, D. Dietrich, A. Leopold, G. Alisch, B. Wielage, Cavitation erosion of electroplated nickel composite coatings, Surface and Coatings Technology 202 (2008) 3967-3974.

[13] E. García-Lecina, I. García-Urrutia, J.A. Díez, J. Fornell, E. Pellicer, J. Sort, Codeposition of inorganic fullerene-like $\mathrm{WS}_{2}$ nanoparticles in an electrodeposited nickel matrix under the influence of ultrasonic agitation, Electrochimica Acta 114 (2013) 859-867.

[14] I. Tudela, Y. Zhang, M. Pal, I. Kerr, A.J. Cobley, Ultrasound-assisted electrodeposition of thin nickel-based composite coatings with lubricant particles, Surface and Coatings Technology 276 (2015) 89-105.

[15] I. Tudela, Y. Zhang, M. Pal, I. Kerr, A.J. Cobley, Ultrasound-assisted electrodeposition of composite coatings with particles, Surface and Coatings Technology 259 (2014) 363-373.

[16] Charles Ross and Son Company, The art of high shear mixing, Whitepaper, (2009).

[17] E. Pullicino, W. Zou, M. Gresil, C. Soutis, The effect of shear mixing speed and time on the mechanical properties of GNP/Epoxy composites, Applied Composite Materials 24 (2017) 301-311.

[18] S. Wang, N. Zhou, F.C. Walsh, Diverse electrodeposits from modified acid sulphate (Watts nickel) baths, Transactions of the IMF 94 (2016) 274-282.

[19] Malvern Instruments Ltd, Zetasizer Nano Series, Product Information (2014). http://www.malvern.com/en/products/product-range/zetasizer-range/.

[20] M. Benali, V. Gerbaud, M. Hemati, Effect of operating conditions and physico-chemical properties on the wet granulation kinetics in high shear mixer, Powder Technology 190 (2009) 160-169.

[21] G. Zhao, Y. Xue, Y. Huang, Y. Ye, F.C. Walsh, J. Chen, S. Wang, One-step electrodeposition of a self-cleaning and corrosion resistant $\mathrm{Ni} / \mathrm{WS}_{2}$ superhydrophobic surface, RSC Advance 6 (2016) 59104-59112.

[22] G. Zhao, J. Li, Y. Huang, L. Yang, Y. Ye, F.C. Walsh, J. Chen, S. Wang, Robust Ni/WC superhydrophobic surfaces by electrodeposition, RSC Adv. 7 (2017) 44896-44903.

[23] J.P. Celis, J.R. Roos, C. Buelens, J. Fransauer, Mechanism of electrolytic composite plating; survey and trends, Transactions of the IMF 69 (1991) 133-139. 
[24] C.S. Chen, H.J. Cian, C.H. Yu, C.W. Huang, Friction coefficient calculation and mechanism analysis for $\mathrm{MoS}_{2}$ nanoparticle from molecular dynamics simulation, Procedia Engineering 79 (2014) 617-621.

[25] H. Wu, L. Qin, G. Dong, M. Hua, S. Yang, J. Zhang, An investigation on the lubrication mechanism of $\mathrm{MoS}_{2}$ nano sheet in point contact: The manner of particle entering the contact area, Tribology International 107 (2017) 48-55. 


\section{Table Caption}

Table 1. Summary of the Ni-MoS 2 composite coatings from literature

Table 2. Composition of a modified Watts nickel bath

Table 3. Conditions used for electrodeposition

\section{Figure Captions}

Figure 1. (a) SEM image of the as-received $\mathrm{MoS}_{2}$ particles, (b) high-shear mixer blade, (c) arrangement for high-shear mixing, (d) cross-section and (e) top plan view of the electrodeposition set-up: 1) cathode, 2) anode, 3) Watts bath, 4) Water bath, 5) magnetic stir bar, 6) magnetic stirrer.

Figure 2. $\mathrm{MoS}_{2}$ particle dispersion in deionised water (a) $2 \mathrm{~h}$ after mixing, (b) $8 \mathrm{~h}$ after mixing.

Figure 3. $\mathrm{MoS}_{2}$ particle Z-average size as a function of: (a) high-shear mixing speed for $1 \mathrm{~h}$, and (b) high-shear mixing time at $8000 \mathrm{rev}^{\mathrm{min}}{ }^{-1}$ compared with magnetic stirring at $2000 \mathrm{rev}$ $\min ^{-1}$

Figure 4. $\mathrm{MoS}_{2}$ particle-size distribution in deionised water after: (a) magnetic stirring, 2000 rev $\min ^{-1}, 3 \mathrm{~h}$, and (b) high-shear mixing, $8000 \mathrm{rev} \min ^{-1}, 3 \mathrm{~h}$.

Figure 5. Examples of (a) pure nickel, (b) Ni-MoS 2 coating via particle dispersion from high-shear mixing $\left(8000 \mathrm{rev} \mathrm{min}^{-1}, 3 \mathrm{~h}\right.$ ) and (c) Ni-MoS 2 coating via particle dispersion from magnetic stirring $\left(2000 \mathrm{rev} \min ^{-1}, 3 \mathrm{~h}\right)$

Figure 6. XRD patterns of: (a) $\mathrm{MoS}_{2}$ powder, (b) pure Ni coating, (c) Ni-MoS 2 composite coating from particle dispersion via high-shear mixing and (d) Ni-MoS 2 composite coating from particle dispersion via magnetically stirring.

Figure 7. SEM and 3D optical images of (a), (c): Ni-MoS 2 coating via particle dispersion from high-shear mixing; (b), (d): Ni-MoS 2 coating via particle dispersion from magnetic stirring. 
Figure 8. SEM and EDX mapping of (a), (c) and (e): Ni-MoS 2 coating via particle dispersion from high-shear mixing; (b), (d) and (f): Ni-MoS 2 coating from a bath involving particle dispersion by magnetic stirring.

Figure 9. Cross-sectional BEI images of coatings on mild steel substrates: (a) Watts nickel coating, (b) Ni-MoS 2 coating via particle dispersion from high-shear mixing and (c) Ni-MoS coating from a bath in which particle dispersion is achieved by magnetic stirring.

Figure 10. Coefficient of friction as a function of test time for Ni-MoS ${ }_{2}$ composite coatings.

Figure 11. Wear track cross-sectional depth profile of (a) $\mathrm{Ni}-\mathrm{MoS}_{2}$ coating via particle dispersion from magnetic stirring and (b) Ni-MoS 2 coating via particle dispersion from high-shear mixing.

Figure 12. 3D optical scans and SEM images of (a), (b) and (c): wear track of Ni-MoS $\mathrm{M}_{2}$ coating via particle dispersion from high-shear mixing; (d), (e) and (f): wear track of Ni-MoS coating from a bath in which particle dispersion was achieved by magnetic stirring. 

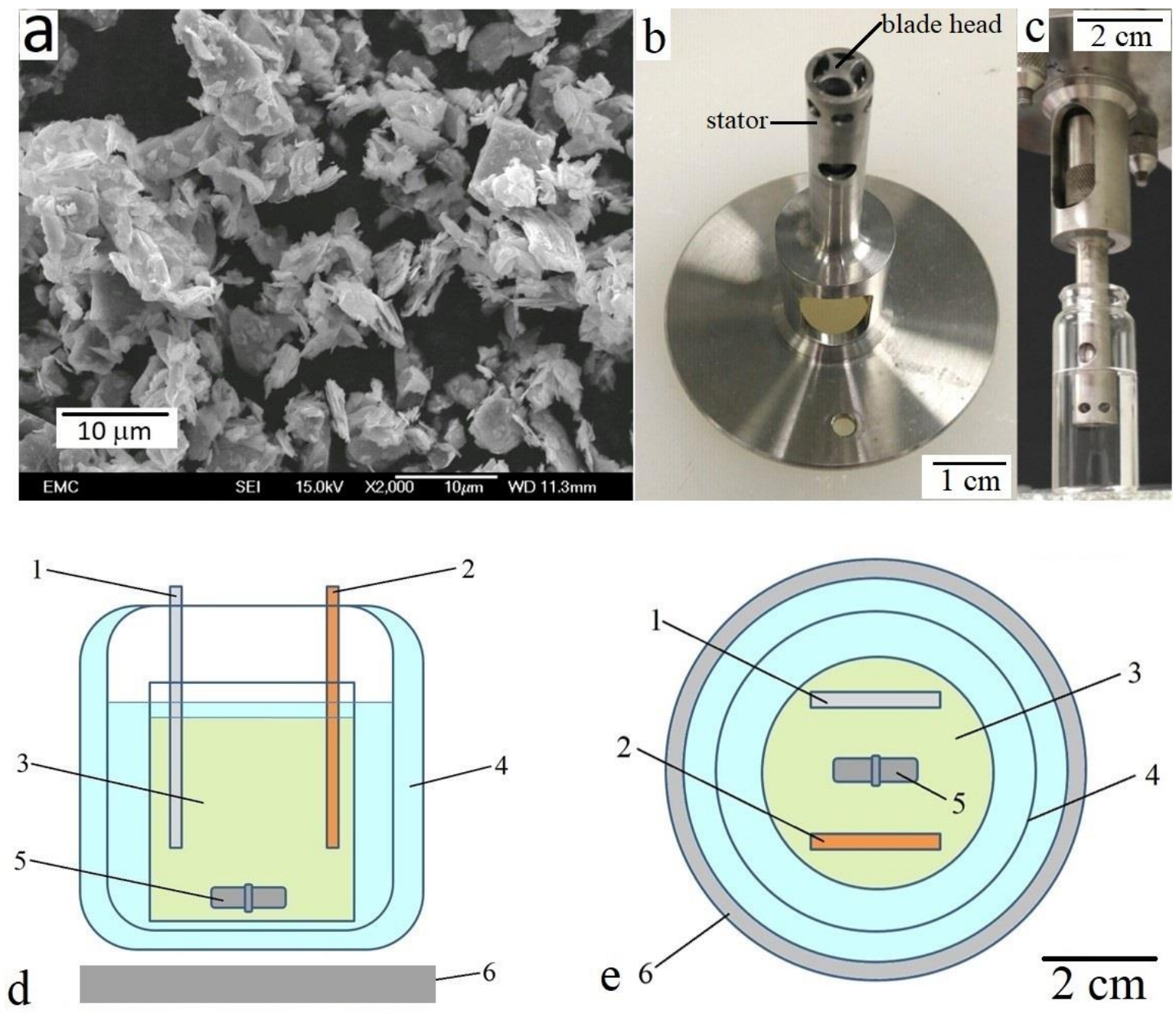


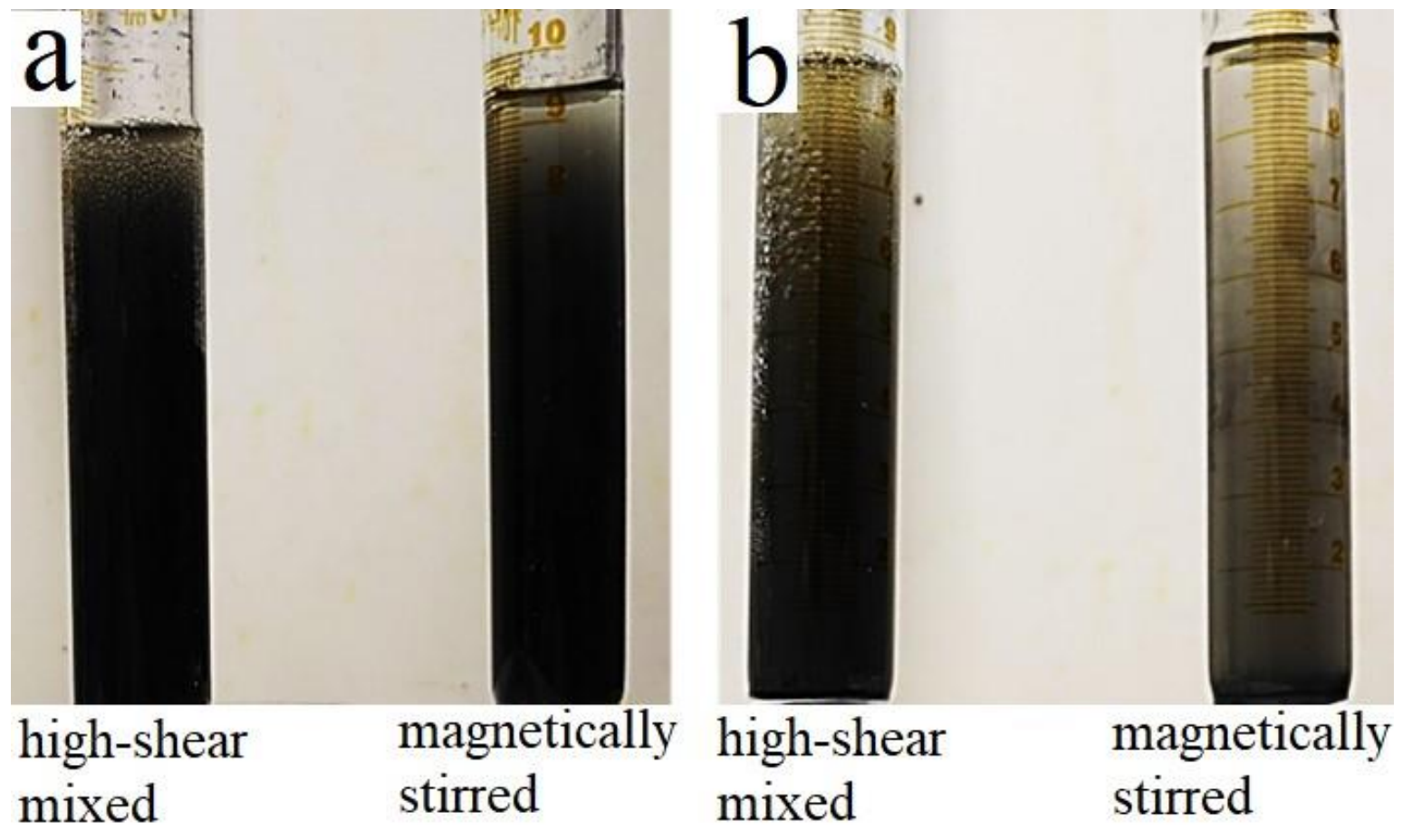



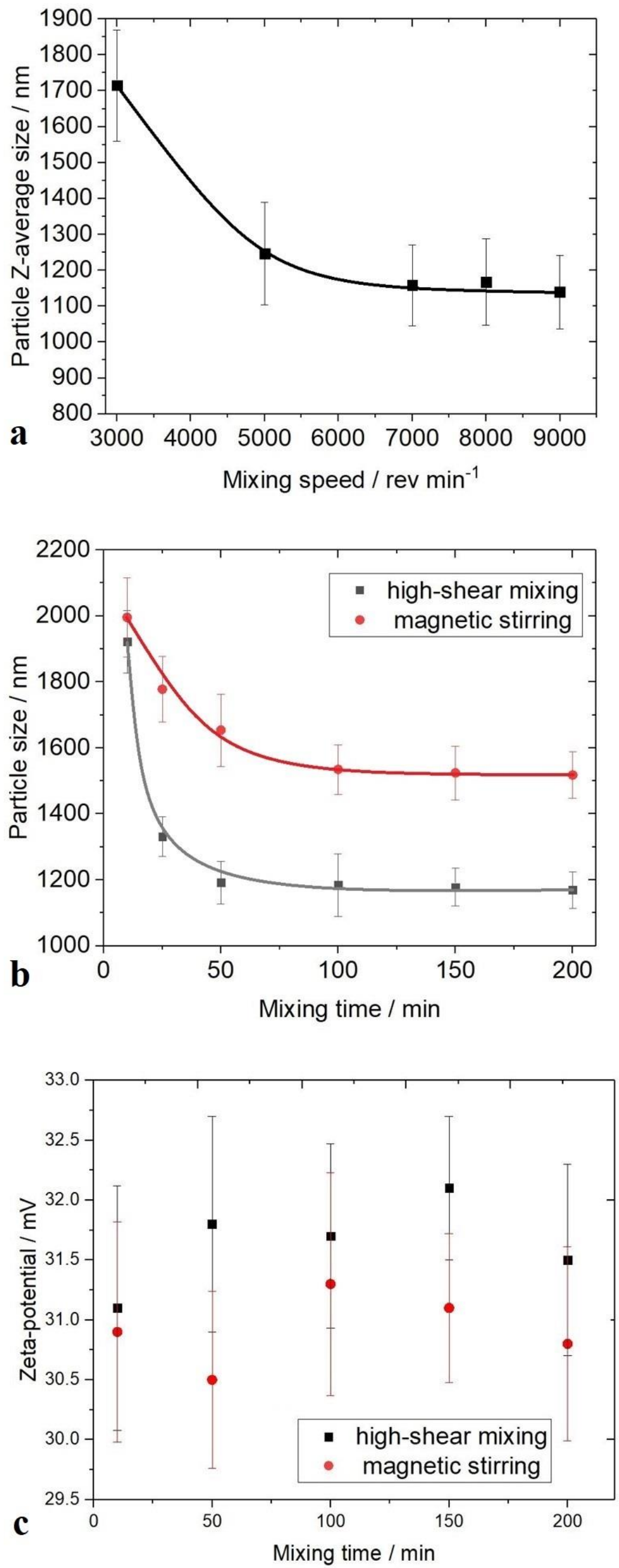
a Size Distribution by Volume

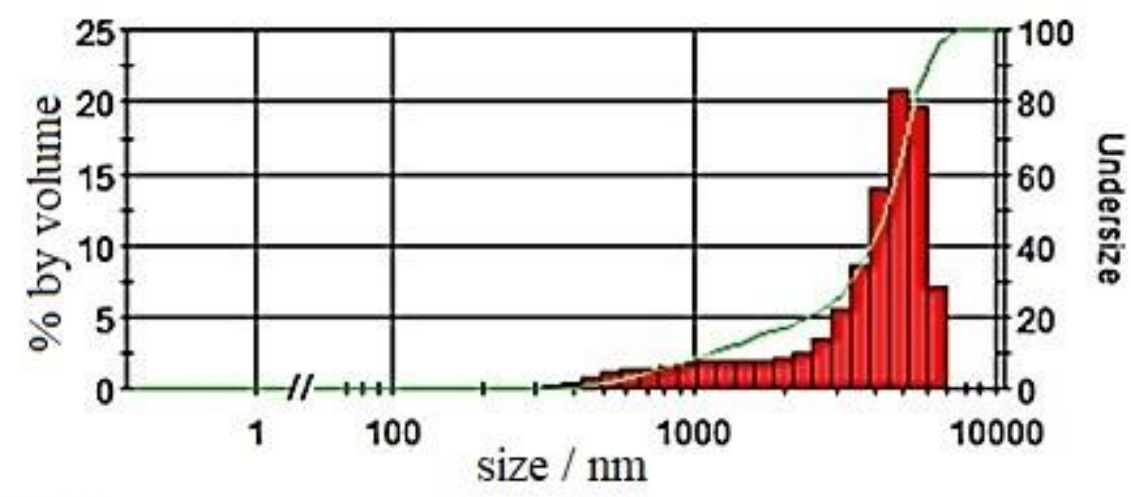

Volume magnetic stirring

Size Distribution by Volume

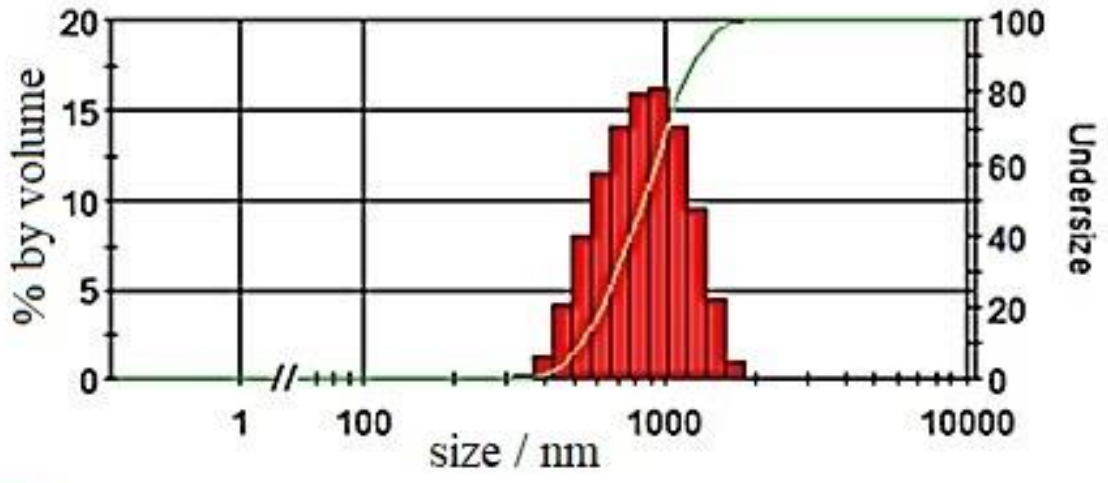

Volume high-shear mixing Undersize culmulative vol\% 


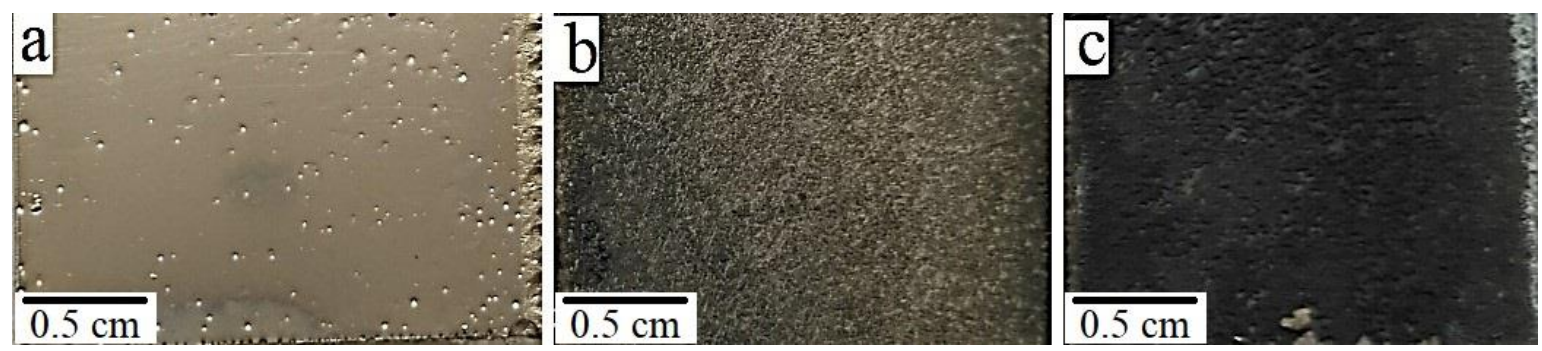




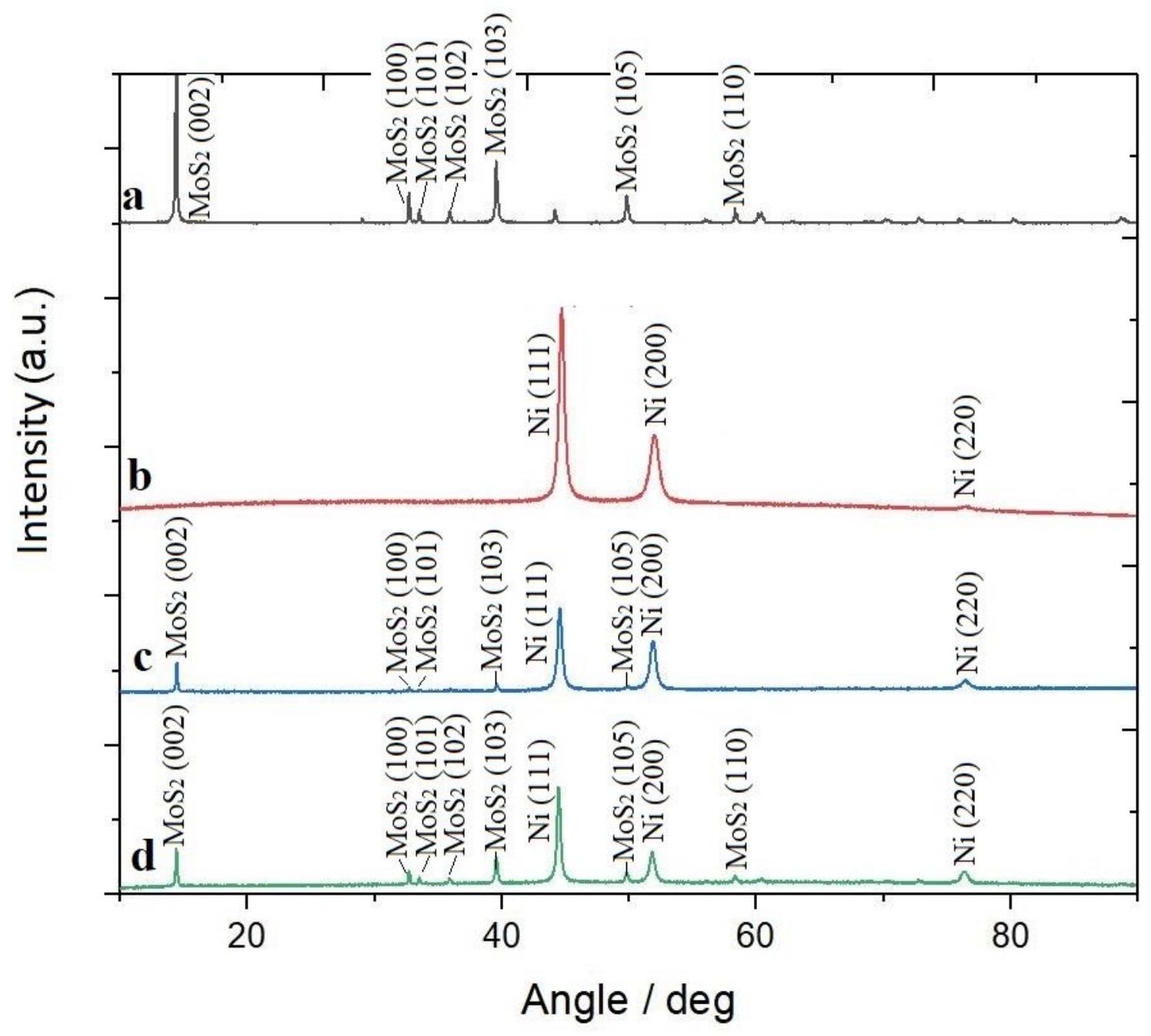



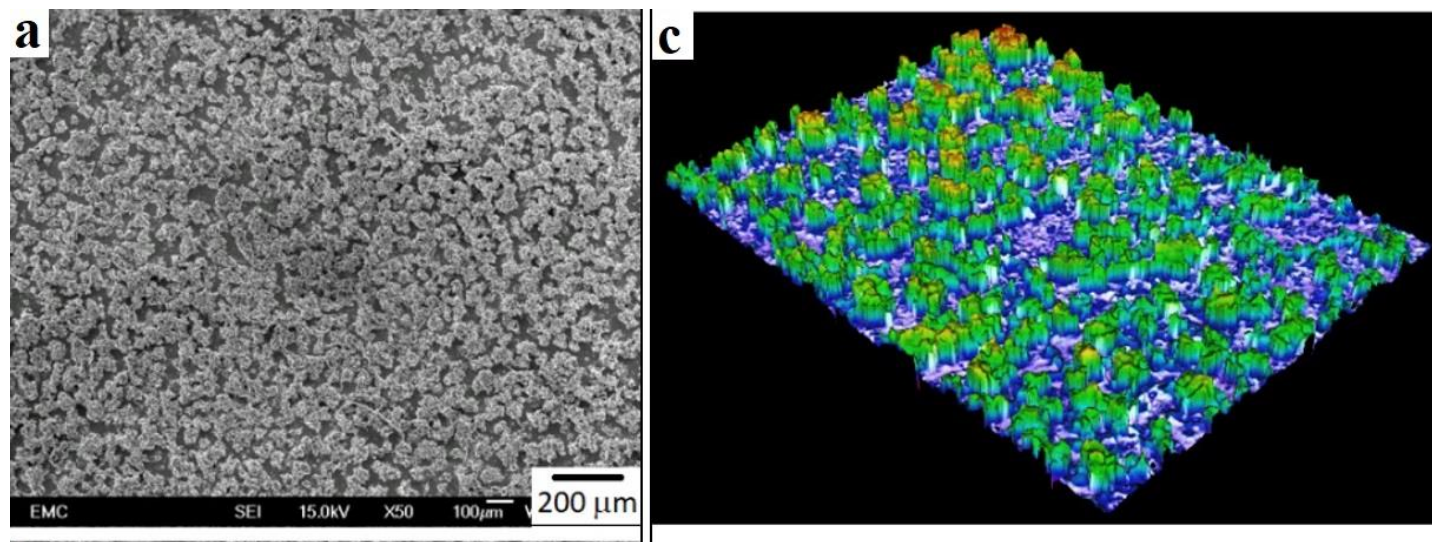

Height
$\mu \mathrm{m}$
80
60
40
20
0
-20
-40
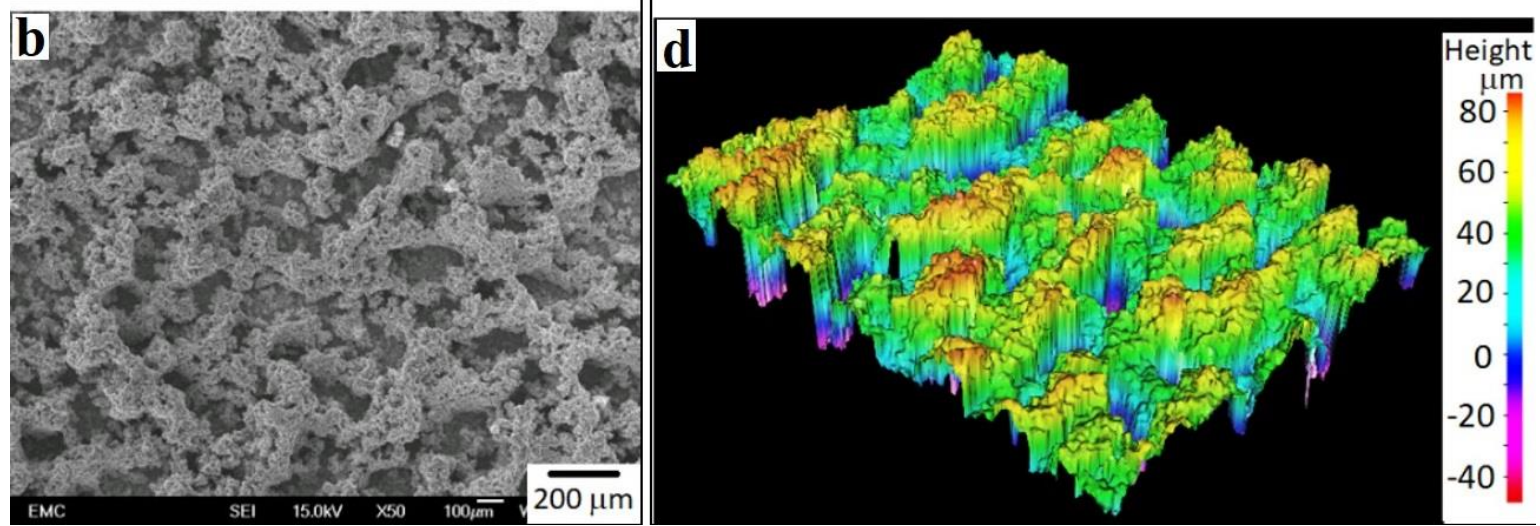

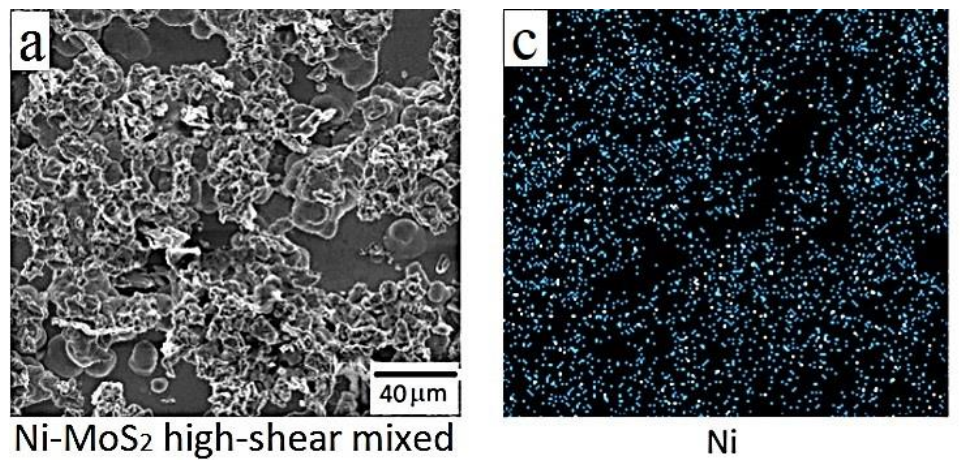

$\mathrm{Ni}$

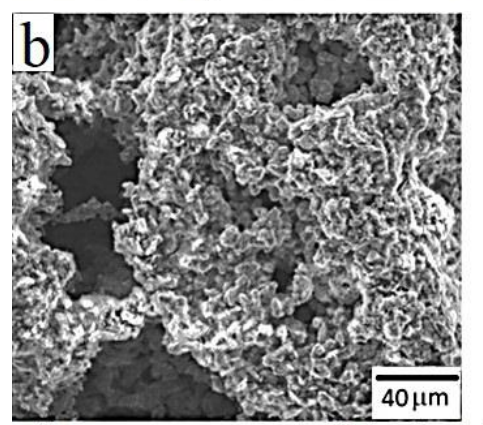

$\mathrm{Ni}-\mathrm{MoS}_{2}$ magnetically stirred

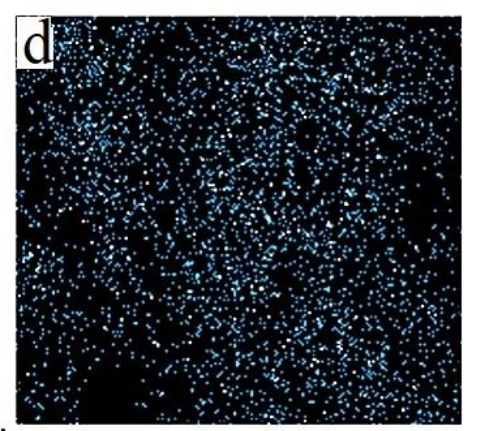

$\mathrm{Ni}$

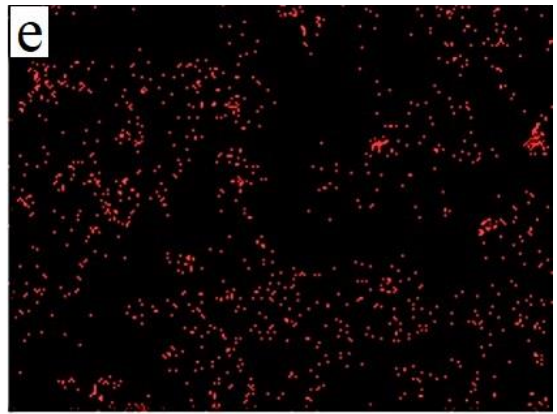

Mo

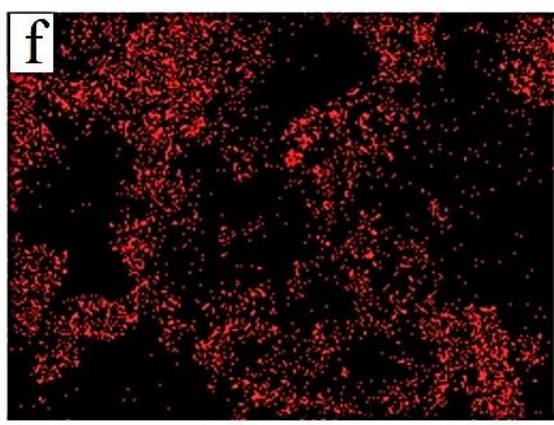

Mo 

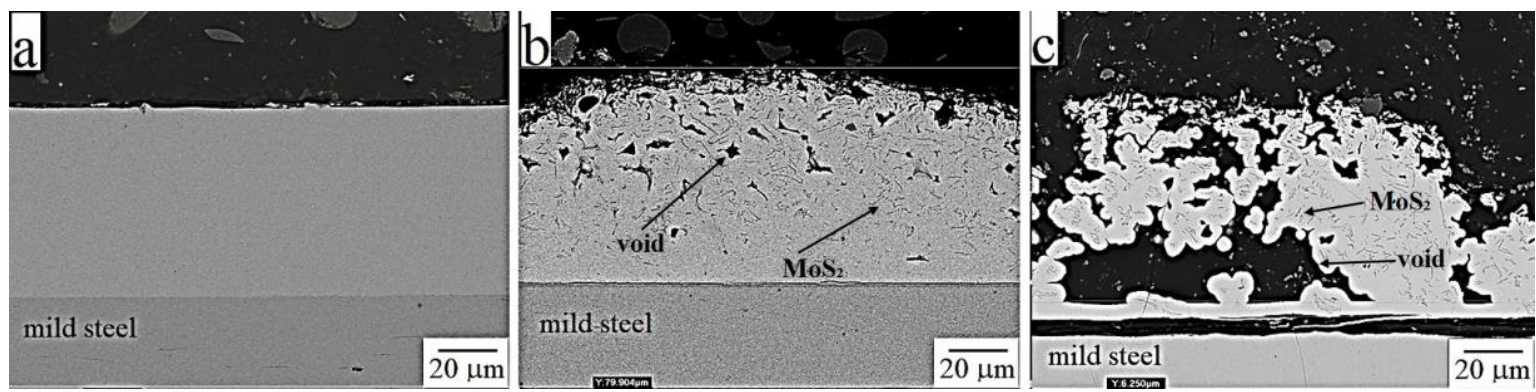


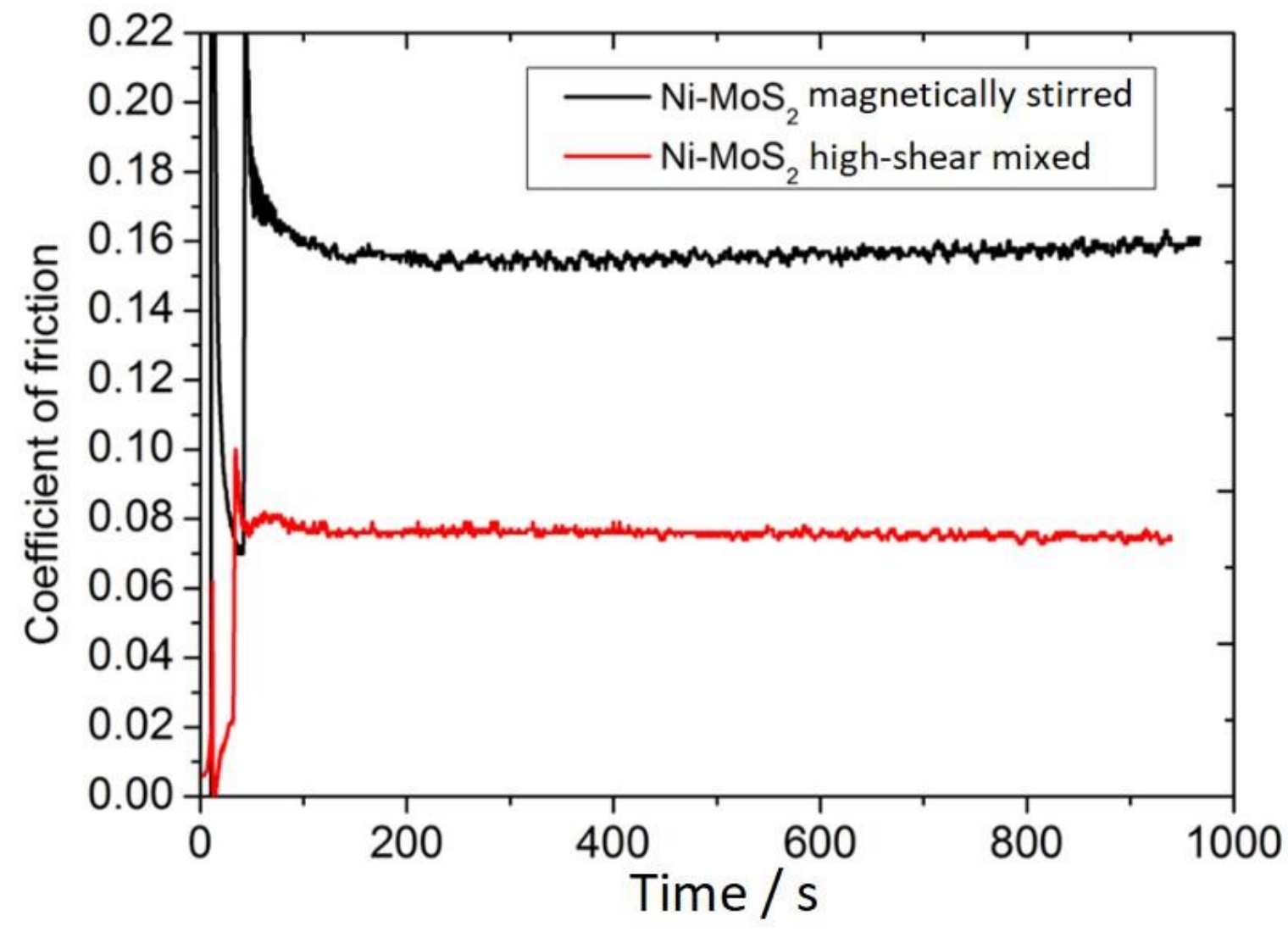




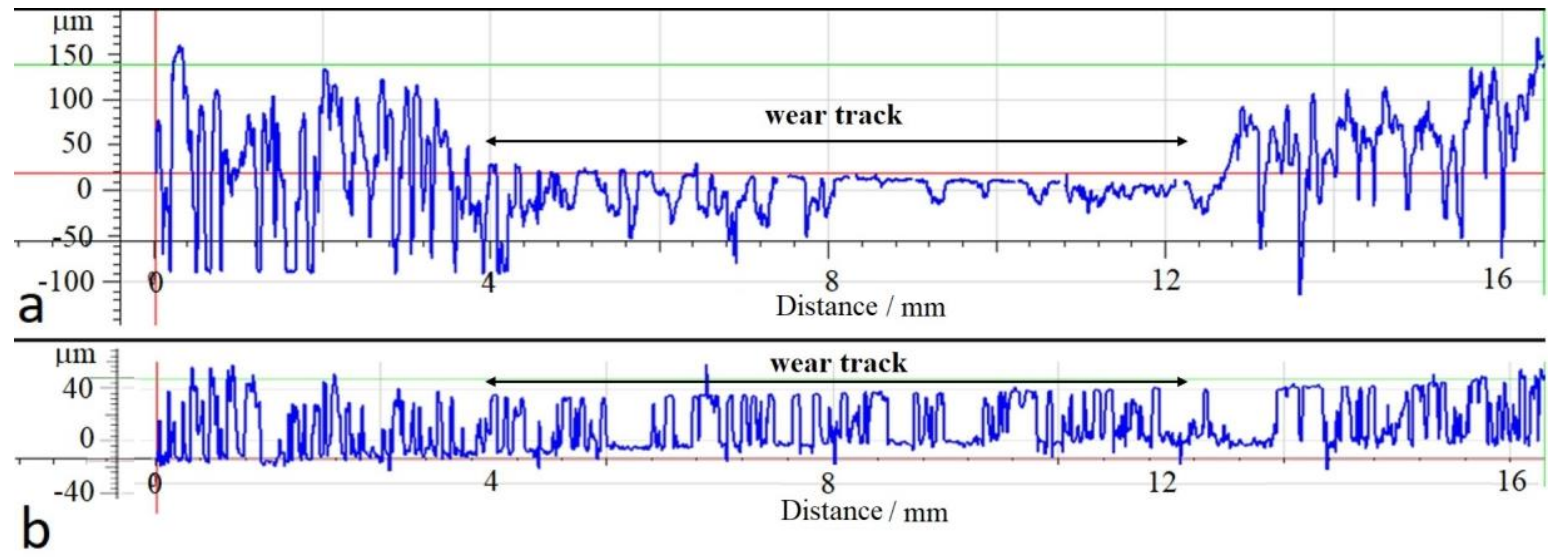



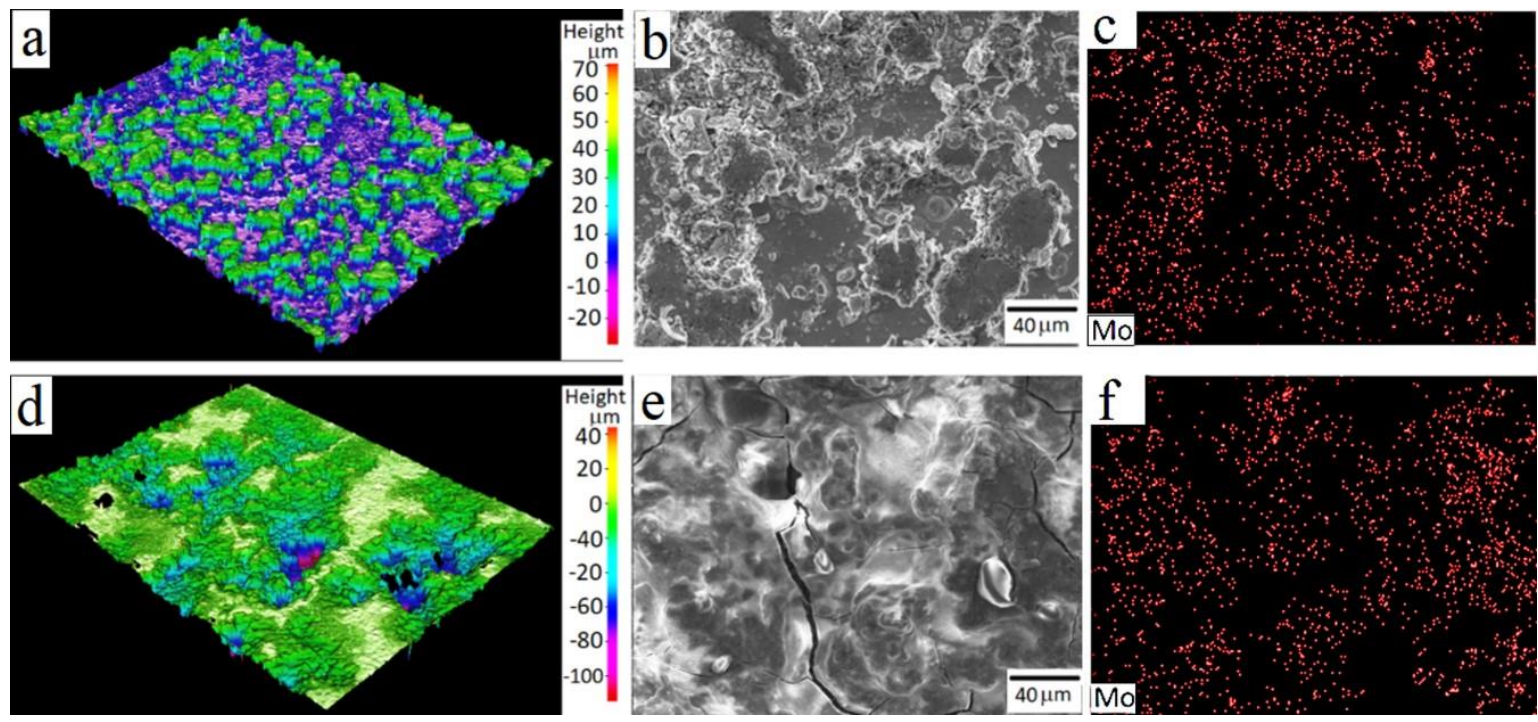